\title{
RATIONAL ATROCITIES AND STATE FORMATION: A GAME THEORETIC APPROACH TO THE CASE OF ISIS
}

\section{Sebastian Ille and Dina Mansour}

Sebastian Ille is Assistant Professor at the Lebanese American University, Beirut, Lebanon. The corresponding author, he can be reached at sebastian.ille@lau.edu.lb. Dina Mansour is Research Fellow at the Orient-Institut Beirut, Beirut, Lebanon, and can be reached atdmansour@aucegypt.edu.

\section{Abstract}

Since Abu Bakr al-Baghdadi announced in April 2013 the formation of the new Islamic polity, the Islamic State of Iraq and Syria (ISIS), it has slowly become the epitome of terror. Certain acts of violence and atrocities committed by ISIS create the impression that it is acting out of blind, destructive religious fanaticism. In contrast, this article argues that this perception is but media-driven speculation. Instead of being religious zealots, ordering the purposeless killing of infidels, ISIS' actions are governed by a strong rationale and a clear aim, namely the creation of a state, moreover one that extends beyond the traditional constitutive elements of statehood. In particular, ISIS' rationality serves the purpose of consolidating an Islamic State in the Middle Eastern region, and beyond, under a Caliphate with a claim to universal governance and jurisdiction. This article illustrates the mechanisms which ISIS uses to achieve its aim of establishing an extended state, and it elaborates on the impact of actions and policies against ISIS on the basis of an evolutionary game theoretic model.

$\mathrm{I}$ n April 2013, Abu Bakr al-Baghdadi announced the formation of an Islamic polity, the Islamic State of Iraq and Syria (ISIS). Since then, it has slowly become the epitome of terror. ${ }^{1}$ Starting with the beheading of a large number of Syrian soldiers in mid-2014 and proclaiming itself on 29 June 2014 as a Caliphate (under a new name: IS, or Islamic State), ISIS has made headlines with numerous similar incidences since then. It seems no day has passed that atrocities committed by ISIS were not part of everyday news worldwide.

As portrayed in the media, "shocking" acts of violence and atrocities committed by ISIS create the impression that it is acting out of blind, destructive religious fanaticism. This article argues that this is a mistaken perception, due to media-driven speculation. Instead of being religious zealots, ISIS' actions are governed by a strong rationale and a clear aim. Its rationality serves the purpose of consolidating, under a Caliphate with universal jurisdiction and entitlement, an Islamic State in the local region, and beyond, whose elements are defined by the Montevideo Convention of 1933 on the Rights and Duties of the State. ${ }^{2}$ ISIS' communications strategy, and especially its use of news and social media, has enabled it to gain worldwide recognition. By posting official videos on YouTube and other social media networks, often uploaded by ISIS members, as well as by releasing statements and posts in at least a dozen languages that can reach up to 90,000 tweets each day, ISIS has achieved unprecedented reach, which also helps with recruitment. More importantly, ISIS' media strategy enabled it to instigate fear in populations inhabiting areas of potential interest to ISIS' expansion strategies. Posting gruesome images and videos of torturing and executing opposing members of local populations as well as of Western journalists and aid workers temporarily paralyzes those populations and makes them easy prey for control and domination. ${ }^{3}$

The growing divide between 6 million Sunnis under a Shi' ia-led government in Iraq, on the one hand, and the Sunni uprising in Syria, on the other, has allowed ISIS to exploit the vacuum of power in these countries. Since Syrian opposition forces are dominated by Jihadi militants, a large portion of the support by Western allies, Saudi Arabia, Jordan, and Qatar was intentionally or unintentionally misdirected into ISIS. In addition, Turkey still opens its borders to allow the flow of weaponry as well as European Jihadi volunteers to enter Syria uncontrolled. By mid-2014, ISIS outflanked al-Qaeda as the most powerful Jihadist/terrorist organization. ${ }^{4}$

To appreciate the dynamics of the model presented in the following section, it is essential to understand that ISIS rationally uses atrocities for two reasons: First, to establish legitimacy as a state with ever-expanding borders and, second, to maintain a situation of strife and conflict so as to assure its grip on and control over local populations. Much like pre-modern modes of state formation, ISIS uses war to carve its imagined state onto the world map. To establish legitimate statehood, ISIS requires both recognition and sovereignty. Recognition of ISIS as an entity is obtained by international 
media coverage and the international community. Atrocities have led the media to create awareness of ISIS' existence and to recurrently portray the Islamic State as a sovereign entity. As a consequence, public opinion is slowly moving in the direction of perceiving ISIS not as a rogue occupying entity of parts of Syria and Iraq, but as a state in its own right. In addition, atrocities help ISIS to appropriate land and impose control over local populations, both vital for its claim to sovereignty. By killing the predominant group in power in each territory that falls into its grip, ISIS is able to create a sectarian regime and to instate its followers as the dominant group in power. In this way, it ensures access to essential sources of capital (e.g., petroleum resources, personal property, and infrastructure) by expropriation and compulsory levy and also establishes a unique identity. This identity is formed out of restructuring the existing culture and integrating it into a fundamentalist, Islamic lifestyle. ${ }^{5}$

In addition, ISIS extends its atrocities to abducting and enslaving women of ethnic and religious minorities. These women represent an alternative to pecuniary remuneration of long-serving fighters and serve as a bait for new recruits. Terror and sexual assault allow ISIS to further tighten its control over seized territory, and instate its own rule and government (U.N. News Centre, 2015). Through atrocities, ISIS thus establishes a pre-modern preliminary governmental structure - a Caliphate - with its own territory, people, legal code, and government, which are the constitutive elements of a full-fledged state. As such, ISIS fulfills the requirements for a sovereign state and, more so, represents itself as a righteous and powerful state. ${ }^{6}$

The establishment of an Islamic State appeals to some Muslims' dream of a Caliphate and represents to many a revival of the Islamic Golden Age. ISIS glorifies itself as a sanctuary for those who feel marginalized in the societies in which they presently live. Thus, ISIS obtains recruits not only by force through conflict, but also from those who live at the margins of other societies. Moreover, ISIS presents itself as the only Islamic entity willing to spread "God's will," by force if necessary. Only a follower of its path can be a "true believer" by fulfilling "God's duty" through jihad. In this way, it affirms its strife for world dominance and for an Islam beyond nationstate borders. Atrocities thereby allow for a reversal of cause and consequence. Instead of seeing foreign intervention as a reaction to the atrocities committed, ISIS presents the conflict as a war between the righteous and true state of God on the one hand, and infidel governments on the other; a fight in the name of God against all worldly evils. Initial victories served as a most welcome proof. In this way, ISIS attracts those who fight in the name of God's will, and punishes those in its path, and
As portrayed in the media, "shocking" acts of violence and atrocities committed by ISIS create the impression that it is acting out of blind, destructive religious fanaticism. The article argues that this is a mistaken perception, due to media-driven speculation. Instead of being religious zealots, ISIS' actions are governed by a strong rationale and a clear aim, namely to establish statehood. An evolutionary game theory model is constructed to study limits and opportunities of opposing ISIS. Special emphasis is given to the role of news and social media.

additionally those who wish to defend (even if with a distorted perception of humanitarian help) God's state against foreign, infidel attacks.

Consequently, we observe that the committing of atrocities are a rational means for ISIS' establishment of a recognized and sovereign state, and also for its consolidation. Atrocities are both a practical and a spiritual necessity. The graver and more abhorrent the atrocities committed, the more ISIS is able to make front-page headlines and force itself onto the foreign policy agendas of governments worldwide. Atrocities are, however, a double-edged sword: Grave human rights violations could trigger military reactions by foreign governments that could potentially destroy ISIS' infant infrastructure, thus hindering its expansion. In addition, an overly drastic or frequent sequence of atrocities increases the probability of a joint, large-scale intervention that may lead to the end of ISIS. As such, ISIS' atrocities are carefully planned, i.e., media-targeted and constructed. In this sense, ISIS follows the idealized homo economicus: Purely self-regarding and self-interested, it creates and uses strife to establish dominion over territory and people to, eventually, become a powerful and recognized state.

To illustrate the rationality behind ISIS' atrocities, we model them as a self-reinforcing mechanism. Atrocities trigger interventions by external governments which weakens ISIS in the short run, but they also lead to an influx of new followers and resources which increases the balance of power in ISIS' favor. Thus strengthened, ISIS then responds with new atrocities and demonstrations of power that enable it to take over new territories, control local populations, and make more headlines worldwide. A level of atrocities that is "too low" as well as a level that is "too high" harms ISIS's interests. Thus, atrocities need to be attuned to domestic political conditions in foreign countries. The model illustrates the dynamic interplay between ISIS and external governments.

\section{The model}

We construct here an evolutionary game theory model that captures the dynamics outlined in the previous section. To keep 
the results tractable, the nonsymmetric game is defined by two player populations. The first is composed of the various factions of ISIS (indicated by subscript $i$ ), and the second is constituted by opponent states (subscript $o$ ), including the U.S., Europe, Saudi Arabia, Egypt, Lebanon, and others. ${ }^{7}$ Let there be two pure strategies for each player. For a faction $i$ of ISIS assume pure strategy set $S_{i}=\left\{s_{i a}, S_{i n}\right\}$, i.e., either commit or refrain from committing atrocities. Each faction of ISIS plays a pure strategy, yet ISIS as an entity plays a convex combination of the pure strategies of its factions, defined by mixed strategy $\sigma_{i}$. Similarly, we assume the pure strategy set $S_{o}$ $=\left\{S_{o i}, S_{o n}\right\}$ for each member state of the opposition, i.e., either to intervene or to refrain from intervention. In this case, a mixed strategy $\sigma_{o}$ defines the severity of intervention of the opponents as an aggregate entity. A payoff function $\pi_{k}\left(s_{k}, \sigma_{j}\right)$ $\in R$ with $j, k=\{i, o\}$ and $k \neq j$ defines the expected payoff of each state or faction $k$ given its own strategy and the mixed strategy of the other population.

First, we define the expected payoffs for the pure strategy sets of each player (i.e., faction or member). Define $x \in(0,1)$ as the share of factions of ISIS which choose to commit an atrocity and $y \in(0,1)$ as the share of intervening member states of the opposition. Consider the following two payoff functions of an ISIS faction when playing, respectively, one of its pure strategies.

$$
\begin{aligned}
& \pi_{i a}=a x+b(\bar{y}-y) \text { if } s_{i}=s_{i a} \\
& \pi_{i n}=-c \text { if } s_{i}=s_{i n}
\end{aligned}
$$

with $a, b$, and $c$ being positive constants. The first part on the right-hand side (RHS) of equation (1a) states that the more frequently and gruesome are the committed atrocities, the higher is the direct return indicated by payoff $a$. Constant $a$ refers to the tighter control of territory, land, resources, and finances that each new atrocity yields, but also to the disruption of incumbent institutions and social structures. The second part of (1a) takes account of the ambivalent effect of committing an atrocity with respect to the opponents' reaction. The value of $\bar{y}$ indicates the threshold below which the faction of ISIS can exploit an intervention. If intervention is half-hearted $(y<\bar{y})$, the faction can present itself as a winner-able to withstand infidel governments - thereby attracting new recruits and sympathy from other countries. ${ }^{8}$ Military intervention on a larger scale $(y>\bar{y})$, however, can damage ISIS' structure and facilities. Parameters $a$ and $b$ also describe the degree to which actions can be exploited in the media, $a$ referring to the shock and awe of decapitations for instance, and $b$ referring to the image of the Islamic State as a refuge for Sunnis and a stronghold against Western immoral societies and Israel. Equation (1b) illustrates that completely refraining from atrocities bears the cost of renouncing the caliphate's universal entitlement which requires continuous expansion in territory and influence, as well as a show of force. The subsequent lack of deterrence and control over its members and finances will cost an ISIS faction an amount of $c .^{9}$

Similarly, the payoff for each of the opposition states' pure strategies are defined by

$$
\begin{aligned}
& \pi_{o i}=d(x-\bar{x})-e y \text { if } s_{o}=s_{o i} \\
& \pi_{o n}=-f x \text { if } s_{o}=s_{o n}
\end{aligned}
$$

with $d, e$, and $f$ defining positive constants. The second part of equation ( $2 \mathrm{a}$ ) represents the growing financial cost of repeated intervention and also the growing likelihood of terrorist attacks that may occur in retaliation. The parameter in the first part, $\bar{x}$, indicates the level of atrocities committed by ISIS below which an intervention is considered detrimental. This is based on two reasons: First, the common suspicion against Western intervention following the Arab Spring events of 2011 requires that ISIS' actions are sufficiently present in the news media to induce Western electorates to support foreign intervention. Second, so long as no clear humanitarian need exists, countries in the Middle Eastern and North African (MENA) region generally disapprove of any interference in their neighbors' internal affairs. Levels of atrocities below a certain threshold $(x<\bar{x})$ make the RHS of (2a) negative, and so would any payoff from intervention. Even at levels of atrocities above the threshold $(x>\bar{x})$, one would need to overcome the cost of intervention $(-e y)$ to make the payoffs positive. (Of course, very low levels of atrocities may occur wholly unperceived, and public opinion may suppose reasons different from humanitarian help as a motivation for intervention.) Equation (2b) states that as the number (or frequency) of atrocities increases, it becomes more costly not to intervene. Nonintervention is considered as a sign of weakness, inviting terror attacks and increasing public disapproval.

We assume repeated interaction between members of both populations, with no specific first nor second mover. We do not assume a random matching of a pair of players from each population, e.g., the U.S. against the faction of al-Qaryatayn, only that opposition forces focus interventions more on territories with a higher level of committed atrocities, and that ISIS conditions its actions on the previous strategy of each state. ${ }^{10}$ Members of each population perceive the actions and outcomes of previous games, but are limited in their cognitive abilities (i.e., memory, degree of rationality, perception). 
Within this context of social interaction, the following type of replicator dynamics offers an adequate approximation of the general decisionmaking process in a social environment. Given any pure strategy $k$ and its frequency $\gamma_{k}$, we define

$$
\gamma_{k}=\gamma_{k}\left(\pi_{k}(\gamma)-\Phi\right)
$$

with $\gamma=\left(\gamma_{1}, \ldots, \gamma_{n}\right)$ and $\pi_{k}(\gamma)$ defining the expected payoff of a player choosing strategy $k$ and $\Phi$ defining the average payoff in the population, given by $\Phi=\Sigma_{j} \pi_{j} \gamma_{j}$. In our case, with two strategies, equation 3 simplifies to

$$
\begin{aligned}
& \dot{x}=x(1-x)\left(\pi_{i a}-\pi_{i n}\right) \text { for ISIS and } \\
& \dot{y}=y(1-y)\left(\pi_{o i}-\pi_{o n}\right) \text { for the opponents. }
\end{aligned}
$$

The replicator dynamics thereby reproduce the effect of social learning. This has a number of advantages over a classic best response play. Players do not choose an optimal strategy immediately, which would require a high degree of rationality and knowledge; instead, players learn how to react over time. Factions and states tend to imitate successful behavior of other factions and states. As a consequence, a payoff maximizing action will diffuse among the leaders of each faction of ISIS and each of the opposition states. The replicator dynamics allow for feedbacks and dynamic adaptation. In addition, the identification of evolutionary stable equilibria imposes an additional refinement criterion, ruling out unlikely Nash equilibria. Equation (4a) states that ISIS will increase its level of atrocities committed whenever doing so grants it a higher payoff than not doing so. For the opponents, equation (4b) states the equivalent with respect to the level of intervention. ${ }^{11}$

Substituting equations (1) and (2) into (4), and simplifying gives

$$
\begin{aligned}
& \dot{x}=x(1-x)(a x+c-b(y-\bar{y})[\text { ISIS }] \\
& \dot{y}=y(1-y)((d+f) x-(d \bar{x}+e y)) \text { [opponents]. }
\end{aligned}
$$

From equations (5), we observe that equilibria occur whenever all members of ISIS and the opponents adhere to a pure strategy, i.e., $x, y=\{0,1\}$. This is a direct consequence of the replicator dynamics and the underlying logic of imitation (i.e., social learning). However, the mixed equilibria are of greater interest. The frequency of atrocities in equation (5a) is stable if $a x+c=b(y-\bar{y})$, i.e., when the gains from committing and increasing the level of atrocities is offset by the cost of intervention of the opponents. Clearly, as long as $y<\bar{y}, x$ converges to 1 . Similarly, for equation (5b) it must hold that $(d+f) x=(d \bar{x}+e y)$, i.e., the benefit of an intervention is exactly offset by its cost.

Solving equations (5) simultaneously, we obtain the following conditions for the interior equilibrium for $x, y \in(0,1)$.

$$
x_{1}^{*}=1, \quad y_{1}^{*}=(d(1-\bar{x})+f) / e
$$

$$
\begin{aligned}
& x_{2}^{*}=\frac{b d \bar{x}+b e \bar{y}+c e}{b(d+f)-a e}, y_{2}^{*}=\frac{a d \bar{x}+(b \bar{y}+c)(d+f)}{b(d+f)-a e} \\
& x_{3}^{*}=\frac{b(1-\bar{y})-c}{a}, \quad y_{1}^{*}=1
\end{aligned}
$$

Consider, first, equation (6a). It states that the equilibrium level of intervention $y_{1}^{*}$ increases in the impact and degree of public support of interventions and the cost of staying out of conflict, and decreases in the maximum cost of intervention. ${ }^{12}$ For this equilibrium to occur on the long run, the maximum costs of intervention need to be higher than the incentives to intervene (i.e., $e>d(1-\bar{x})+f)$. In addition, the equilibrium needs to be evolutionarily stable, i.e., small fluctuation (e.g., due to some trial and error by ISIS and its opponents) do not cause players to shift away from their equilibrium play. The eigenvalues of the Jacobian at $\left(x_{1}^{*}, y_{1}^{*}\right)$ are: ${ }^{13}$

$$
\begin{aligned}
\lambda_{11} & =\frac{(d(1-\bar{x})+f)(d(1-\bar{x})+f-e)}{e} \\
& =y_{1}^{*}\left(y_{1}^{*}-1\right) e \\
\lambda_{21} & =\frac{b(d(1-\bar{x})-e \bar{y}+f)-e(a+c)}{e} \\
& =b\left(y_{1}^{*}-\bar{y}\right)-(a+c)
\end{aligned}
$$

The first eigenvalue is strictly negative. For the second to be negative, either $\bar{y}$ has to be sufficiently large or $b$ sufficiently small, i.e., interventions need to reach high levels before they harm ISIS or generally have only a minimal effect.

Equation (6c) states that the equilibrium level of atrocities $x_{3}^{*}$ falls as the benefit of atrocities for ISIS increases, the cost of committing no atrocities increases, or the possibility of exploiting interventions increases. ${ }^{14} \mathrm{We}$ have the following eigenvalues

$$
\begin{aligned}
\lambda_{13} & =\frac{(b(1-\bar{y})-c)(a+b(\bar{y}-1)+c)}{a} \\
& =x_{3}^{*}\left(1-x_{3}^{*}\right) a
\end{aligned}
$$




$$
\begin{aligned}
\lambda_{23} & =\frac{a(d \bar{x}+e)+(c-b(1-\bar{y}))(d+f)}{a} \\
& =(e+d \bar{x})-\left(x_{3}^{*}(d+f)\right.
\end{aligned}
$$

Here, the first eigenvalue is strictly positive for $x<1$, thus the fixed point is unstable and no evolutionarily stable equilibrium exists. ${ }^{15}$ A similar analysis of the remaining fixed points reveals that the cases $(x=0, y=0),(x=1, y=0)$, and $(x=0, y=1)$ are unstable fixed points as well. This is intuitive when looking at equations (5). In the absence of any intervention, it is not a best response by all ISIS factions to abstain from atrocities. Similarly, it is not a best response of the opponents to intervene at full scale in the absence of atrocities, nor to intervene if the level of atrocities is high.

The escalation case $\left(x_{4}^{*}=1, y_{4}^{*}=1\right)$ is, however, only a stable attractor if

$$
\begin{aligned}
& e<f+d(1-\bar{x}) \\
& b(1-\bar{y})<a+c .
\end{aligned}
$$

Inequality (9a) states that the maximum cost of intervention must be smaller than the maximum net cost of nonintervention; equivalently, inequality ( $9 \mathrm{~b}$ ) states that the cost of a full-scale intervention for ISIS must be less than the net benefit of committing the highest level of atrocity. In the case in which $\left(x_{4}^{*}, y_{4}^{*}\right)$ is stable, the mixed equilibrium defined by equation (6a) does not exist.

The eigenvalues of the completely mixed equilibrium defined by equation (6b) are too complex to be studied in this general manner. Instead, Figure 1 illustrates the eigenvalues with respect to the direct benefits from atrocities $a$ and the impact of external intervention on ISIS' payoff indicated by $b$.

We observe a similar pattern for different values of $i$. The eigenvalues strictly increase in $a$ and have a negative real part for small values. At larger values of $a$, the real part turns positive, and the discriminant eventually becomes positive. ${ }^{16}$ Thus, at small values of $a$ (or at large values of $b$ ) the system spirals toward the interior equilibrium. As the returns of atrocities for ISIS increase (at larger values of $a$ or smaller values of $b$ ) the system spirals away from the equilibrium. For even larger values of $a$, the discriminant is strictly positive (indicated by the splits in the graphs). At this point, the system will noncyclically diverge from the equilibrium. A similar analysis for $c$ reveals that a rise in the cost of committing no atrocity decreases the maximum $a$ for which the interior equilibrium is an attractor. Hence, the strictly mixed equilibrium is stable if either the benefits from atrocities or the (a) $b=8$

(b) $b=12$ (c) $b=16$

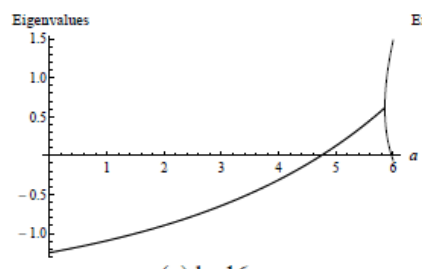

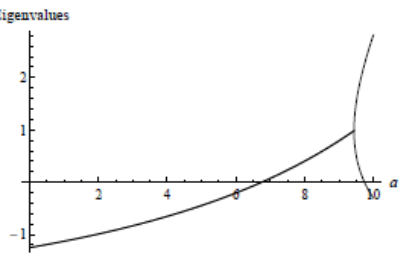

(d) $b=20$

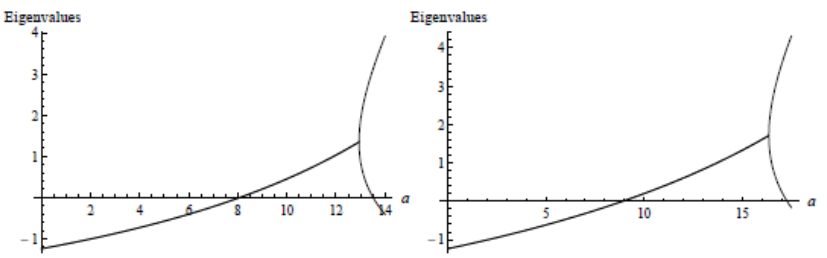

Figure 1: Real parts of the eigenvalues of equation (6b) for various values of $b$ and $a$ as defined by the unit interval of $(x, y)$, given $c=1$, $d=20, e=10, f=2, \bar{y}=0.4$ and $\bar{x}=0.2$.

costs of refraining from atrocities are small, or if the impact of foreign intervention is high.

Figure 2 illustrates the interplay of the opponents' parameters. Each row analyzes the relation between the impact of atrocities (i.e., on public opinion) and the costs of intervention, $e$, for one of the three cases (positive real part, negative real part, and positive discriminant). We generally observe that larger costs of intervention, $e$, support, whereas higher benefits from committing atrocities, $a$, impede the stabilizing effect of a higher impact of public opinion, $d$. Thus, for the interior equilibrium to be stable in the presence of high gains from atrocity, the cost of intervention and the impact of public opinion need to be high as well.

These results provide an indication of the parameters' effect on the stability and occurrence of the system's equilibria and thus on the long-run outcome. On this basis, the following section illustrates the expected effect of policies and changes to the environment in which both players interact.

\section{Implications}

The model presented in the prior section illustrates that the system can converge to one or two equilibria in the long run [i.e., either equilibrium $\left(x_{1}^{*}, y_{1}^{*}\right),\left(x_{2}^{*}, y_{2}^{*}\right)$ or $\left(x_{4}^{*}, y_{4}^{*}\right)$, and where the first and last cannot occur simultaneously]. Figure 3 exemplifies the equilibrium of complete escalation, fulfilling the conditions of equations (9).

The vector field in Figure (3a) illustrates the system's dynamics. The red line indicates all loci at which $\dot{x}=0$, the green line all loci at which $\dot{y}=0$. To the left of the red line, $x$ decreases, to the right $x$ increases; the same for $y$ with respect to the green line. Starting out from the unstable interior 
equilibrium defined by the intersection of both lines, the system cyclically converges to $x$ $=1, y=1 .{ }^{17}$ No other point is stable. The dynamics are illustrated in Figures $3 b$ and $3 c$. In this case, we observe that although each intervention reduces the level of atrocities in the short run, it sequentially causes new and stronger incidents of atrocity to which the opponents react with new interventions. In this case, any intervention will have an effect opposite to its intent. Further, note in Figures $3 \mathrm{~d}$ and $3 \mathrm{e}$ that both players would be roughly equally well off at the unstable equilibrium $(x=0, y=0)$. However, ISIS has an incentive to shift to a strategy of atrocities in the absence of any risk of intervention, which will affect the opponents' best response. However, in the case in which the opponents are able to credibly convince ISIS that they will react to any atrocity with a full intervention, then an outcome close to $x=0, y=0$ could be maintained.

The first row of Figure 4 illustrates the same case as before except for a larger impact of interventions on ISIS' payoff (a change from $b=12$ to $b=20$ ). We observe that now the completely mixed equilibrium is an attractor, and thus the system spirals into the interior. Note the shift in the red $\dot{x}=0$ loci, which now intersects with the right ordinate. In this case, an intervention by the opponents will show an effect. However, the interior equilibrium is defined by a persistent average level of intervention and atrocities. We observe that the position of the interior equilibrium is essentially defined by the values of $\bar{x}$ and $\bar{y}$. A low benefit from intervention

(a) $\mathrm{a}=3$, e=0

(b) $\mathrm{a}=3, \mathrm{e}=10$

(c) $\mathrm{a}=3, \mathrm{e}=20$

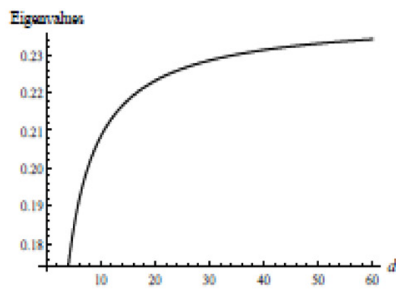

(d) $\mathrm{a}=14, \mathrm{e}=0$

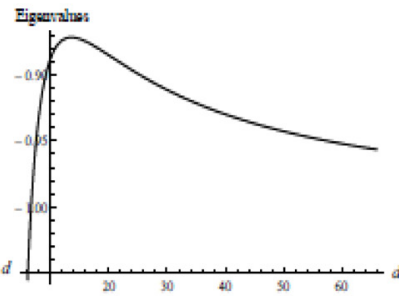

(e) $\mathrm{a}=14, \mathrm{e}=10$

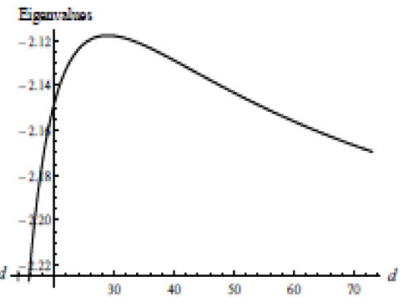

(f) $a=14, e=20$

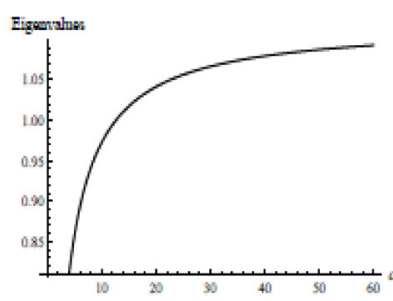

(g) $\mathrm{a}=20, \mathrm{e}=0$

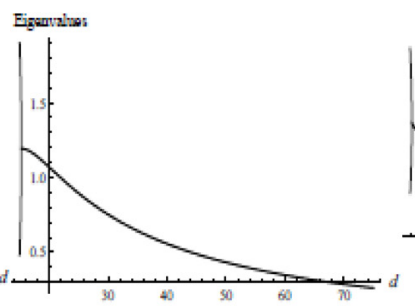

(h) $\mathrm{a}=20, \mathrm{e}=10$

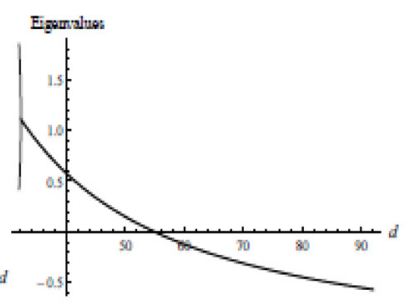

(i) $\mathrm{a}=20, \mathrm{e}=20$

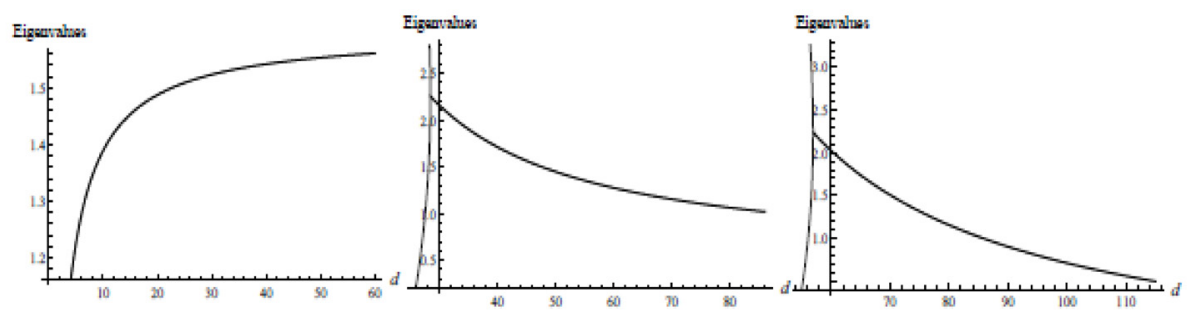

Figure 2: Real parts of the eigenvalues of equation (6b) for various values of $a, d$, and $e$ as defined by the unit interval of $(x, y)$, given $b=20, c=1, f=2, \bar{y}=0.4$ and $\bar{x}=0.2$.

(a) Vector field

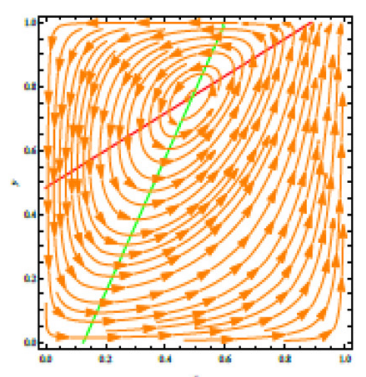

(d) Payoff Plot ISIS

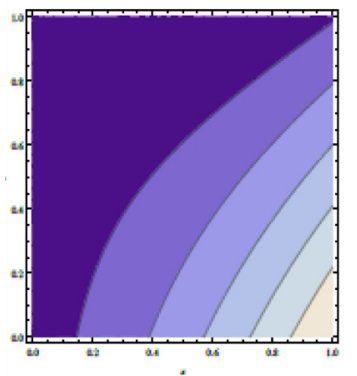

(b) Evolution Unit Simplex (c) Evolution over 30 periods, blue $\rightarrow \mathrm{x}$, violet $\rightarrow \mathrm{y}$
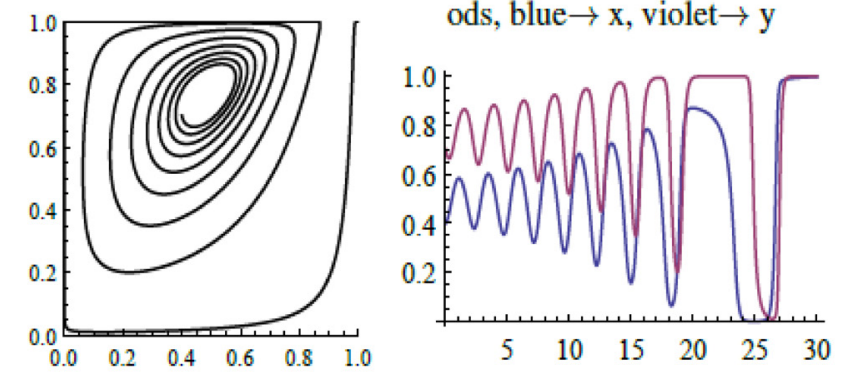

(e) Payoff Plot Opponents
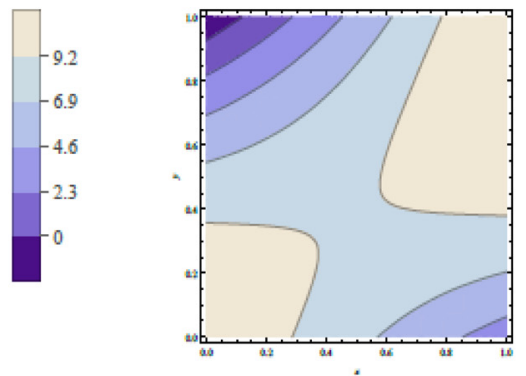

Figure 3: Escalation: $a=7, b=12, c=1, d=12, e=9, f=7, \bar{y}=0.4, \bar{x}=0.2$. 
(e.g., by closing borders, changing public opinion, and limiting access to social media), as well as an increase in the support for interventions at lower levels of atrocities will bring down both values. This case is illustrated in the second row of Figure 4. Both interventions and atrocities shift down to very low levels within a short time. This result is interesting since we would assume that a higher acceptance of interventions (a lower $\bar{x}$ ) would cause the equilibrium to also shift up to higher levels of intervention. The high support for interventions serves as a credible threat which keeps atrocities low and therefore does not require further interventions. A lack of public support (an $\bar{x}$ close to 1), on the other hand, implies also a high acceptance for ISIS' atrocities, which shifts the latter's best response and will lead to higher levels of atrocities (see third row of Figure 4). Looking at the vector field shows that up to relatively high levels of atrocity no intervention is the best response. The change in the opponents' best response is illustrated by the movement of the green $\dot{y}=0$ loci. Since ISIS experiences only little reaction by the opponents, it will commit an increasing number of atrocities. The fourth row illustrates the case in which public support is high, but ISIS is able to benefit from interventions. This situation leads to a destabilization of the interior equilibrium, and the system will escalate. ${ }^{18}$

Indeed, public opinion turns out to be a double-edged sword. Increasing the effect of public opinion on the intervention decision can render both the interior and the escalation equilibrium stable. Increasing impact $d$ in the example in Figure 3 yields the situation illustrated in Figure 5. The long-run results depend on the initial values of $x$ and $y$. The figure illustrates both cases with the same parameters but different initial values. By looking at the vector field, we observe that the basin of attraction of the interior equilibrium covers the northwestern part of the unit simplex; the basin of attraction of the escalation equilibrium covers the southeastern part. Consequently, if opponents initially underreact $\left(y_{0}\right.$ is small), then the system will escalate. The escalation equilibrium is stable, whenever the red line (i.e., the $\dot{x}=0$ loci) does not intersect with the ordinate on the right but with the abscissa on top (also observe that the loci are equivalent to Figure 3). Since the real part of its eigenvalues are negative $(-0.1038)$, any point in the basin of attraction of the interior equilibrium spirals toward the point as defined by equation (6b). Thus at sufficiently high initial levels of interventions, a full escalation can be avoided and the frequency of atrocities be stabilized at lower levels. Equation (7b) tells us that the equilibrium on the right edge of the unit simplex is stable if $b\left(y_{1}^{*}-\bar{y}\right)<(a+c)$. Note that as long as $y_{1}^{*}<\bar{y}$, ISIS benefits from an intervention at the equilibrium level and the inequality is fulfilled. Even if ISIS loses by the opponents' intervention, (a) Vector field

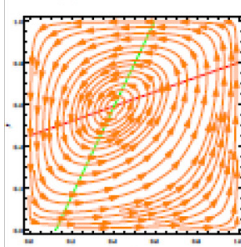

(d) Vector field

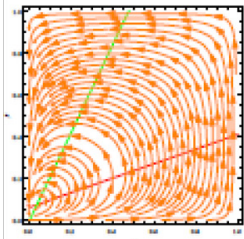

(g) Vector field

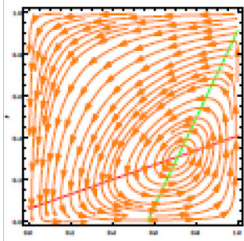

(j) Vector field

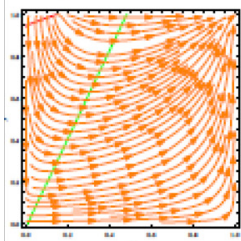

(b) Evolution Unit Simplex (c) Evolution over 30 peri-

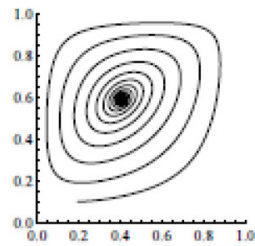

(e) Evolution Unit Simplex

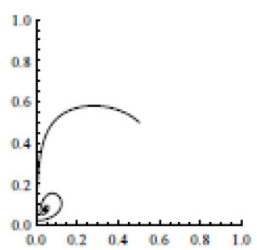

(h) Evolution Unit Simplex
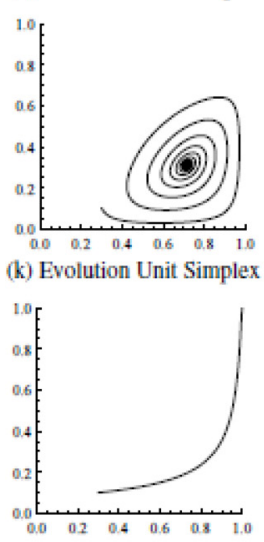

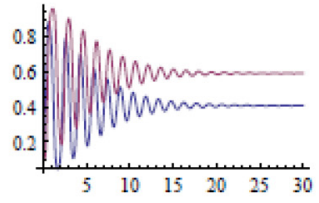

(f) Evolution over 30 periods, blue $\rightarrow x$, violet $\rightarrow y$

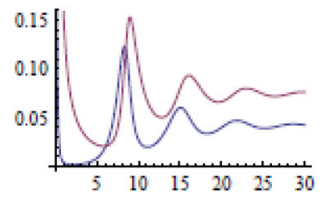

(i) Evolution over 30 periods, blue $\rightarrow x$, violet $\rightarrow y$

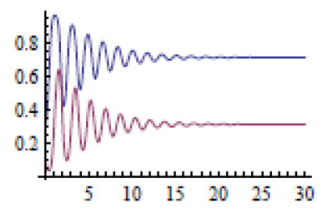

(1) Evolution over 5 periods, blue $\rightarrow x$, violet $\rightarrow y$

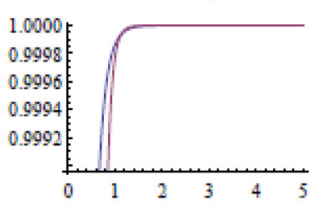

ods, blue $\rightarrow x$, violet $\rightarrow y$

Figure 4: Interior equilibrium: $a=7, b=20, c=1, d=12, e=9, f=$ 7 , first row $\bar{y}=0.4, \bar{x}=0.2$, second row $\bar{y}=0.01, \bar{x}=0.01$, third row $\bar{y}=0.01, \bar{x}=0.9$, fourth row $\bar{y}=0.9, \bar{x}=0.01$.

the condition holds as long as this loss is smaller than the net benefit from committing a maximum level of atrocities. In addition, we require by equation (6a) that $e>d(1-\bar{x})+f$. Both clearly hold for situations in which $\bar{x}$ and $\bar{y}$ are close to 1. Thus, if support for an intervention is low, but ISIS benefits from any action taken by the opponents, ISIS will choose a best response of $x^{*}=1$, and the opponents some level of intervention arbitrarily close to $f / e$ (the ratio of the cost of not intervening to the cost of intervention). The same result occurs if the public does not pay any attention to ISIS' actions $(d=0)$, and if the repercussions of not intervening (e.g., because of strong intelligence in these countries and low risk of suicide bombers) are negligible. In this case, the level of intervention is low and ISIS will find it best to maximize its level of atrocity. This situation is illustrated in Figure 6.

Reducing the opportunities to exploit the benefits from committing atrocities can stabilize the interior equilibrium as indicated by the results of Figure 2 and condition (9b). In this case, only the benefits derived from the oppositions' interventions offer an incentive for ISIS to commit atrocities, 
and the system's dynamics are primarily defined by the values of $\bar{x}$ and $\bar{y}$ (as already implied by Figure 4). Figure 7 illustrates this case.

These results imply that curtailing the direct benefits does not necessarily imply that atrocities will cease. Additional conditions need to be met. For equation (7b) to be positive, and thus for inequality (9b) not to hold, it is required that the impact of interventions is effective and enduring. In addition, low levels of $\bar{x}$ and $\bar{y}$ imply that ISIS should have a limited capacity to exploit the opponents' actions in its favor, and that the opposition should have sufficient public support for eventual interventions.

\section{Conclusion}

That ISIS has been committing seemingly unjustified atrocities throughout the MENA region, and has done so continuously, has made it a frequent topic within foreign policy circles and on media platforms. This article examines the rationality and the ends behind the atrocities committed by ISIS as well as the means it has employed to justify them. The means in this case are the atrocities themselves, which we argue are strategically employed to enable ISIS to achieve its aim of acquiring land and legitimacy - two essential elements for the formation of a state. Based on this rationale, we argued and illustrated that an inadequate reaction of the opposition to ISIS' actions can lead to an escalation and a spiral of violence and terror.

The article has elaborated what we argue to be the most likely reasons behind ISIS' actions. On the basis of an evolutionary game theoretic model, we have studied the effect of changes to the conditions under which ISIS and its opponents interact. It turns out that reducing ISIS' ability to seize land, resources, and people is only a first step - and one that is not sufficient to reduce the level of atrocities committed. In order to minimize atrocities and conflict, the model's results translate into a set of actions that focus simultaneously on a number of (a) Vector field

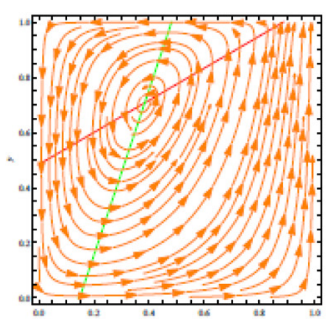

(b) Evolution Unit Simplex

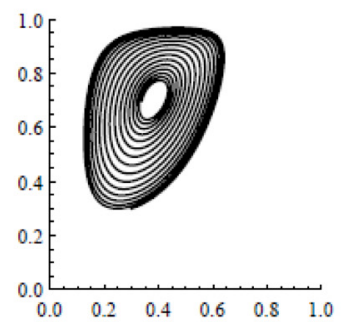

(c) Evolution over 30 periods, blue $\rightarrow \mathrm{x}$, violet $\rightarrow \mathrm{y}$

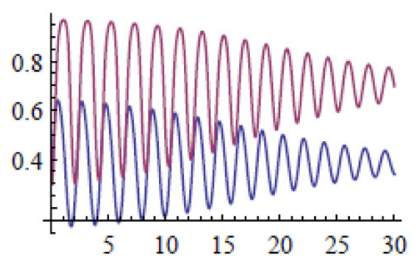

(d) Evolution Unit Simplex (e) Evolution over 30 peri-

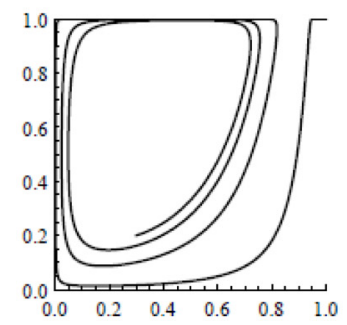
ods, blue $\rightarrow \mathrm{x}$, violet $\rightarrow \mathrm{y}$

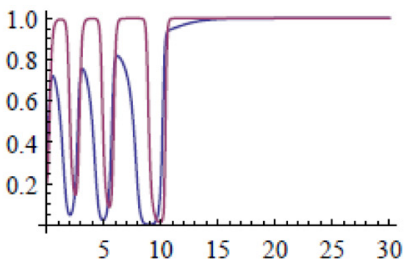

Figure 5: Public opinion: $a=7, b=12, c=1, d=20, e=9, f=7, \bar{y}=0.4, \bar{x}=0.2$, first row $y_{0}=0.3, x_{0}=0.3$, second row $y_{0}=0.2, x_{0}=0.3$. (a) Vector field

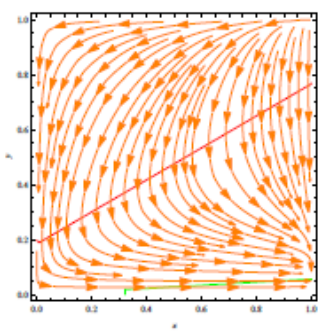

(b) Evolution Unit Simplex

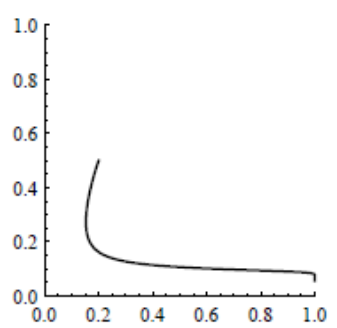

(c) Evolution over 30 periods, blue $\rightarrow \mathrm{x}$, violet $\rightarrow \mathrm{y}$

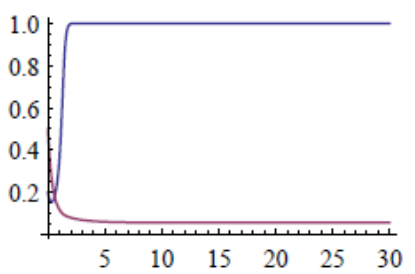

Figure 6: Low intervention: $a=7, b=12, c=1, d=0, e=9, f=0.5, \bar{y}=0.1, \bar{x}=0.3$. (a) $\bar{x}=0.2, \bar{y}=0.4$

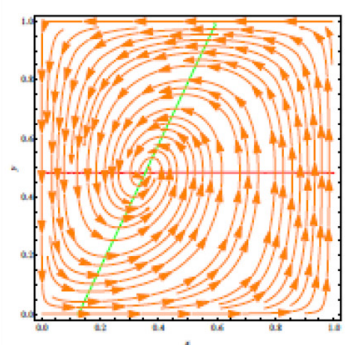

(b) $\bar{x}=0.1, \bar{y}=0.1$

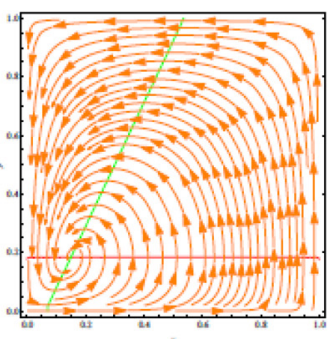

(c) $\bar{x}=0.9, \bar{y}=0.7$

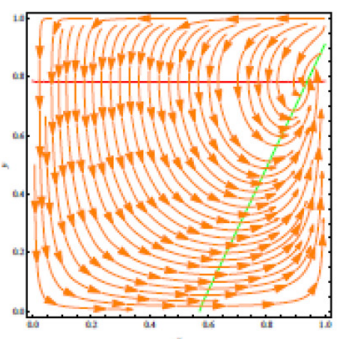

Figure 7: Low gains from atrocities: $a=0.001, b=12, c=1, d=0, e=9, f=0.5$.

variables. Most of these have already been debated as individual actions in the media. For example, the development of effective and well-targeted interventions that would severely harm ISIS' infrastructure, along with public awareness of the 
necessity for such interventions, creates a credible threat to ISIS' very existence which, in turn, would discourage it from committing atrocities beyond a certain threshold. In this case, no strong intervention measures would be necessary. The most crucial element, however, regards ISIS' capacity to capitalize on interventions. To limit this capacity, we propose actions such as closure of the Turkish border, imposing an entry-exit tracking system, and limiting ISIS' access to public and online media. In fact, limiting access to the latter is a crucial element since ISIS uses social media networks and videos to attract followers, sympathizers, and, above all, unwarranted attention. Restricting media access would also derogate public awareness and support. True, low public awareness and exposure may give ISIS a "free hand" to escalate violence, but this would go largely unexposed and unremarked and hence be of limited use to ISIS.

As such, the role of the media turns into a doubled-edged sword. Strong media sensitivity to ISIS' actions may lead to either escalation or pacification. If the opposing states initially underreact to atrocities, ISIS will extend them, which leads to a spiral of violence, i.e., a cycle of more atrocities and stronger reactions. Conversely, an adequate initial intervention will cut short the cycle of conflict and will ease the situation.

Moreover, the direct acquisition of land, resources, and people may only be a temporary requirement for ISIS to establish its long-awaited universalist aspiration to form a recognized Caliphate. Following Sayyid Qutb's vision of what he termed the universal law, ISIS' current scale of recruitment and use of social media can be enough to create agents and supporters of its ideology lasting much longer than ISIS' own lifetime. Such agents and supporters within and outside the Middle East, if found in larger groups, may force a revival of ISIS literally anywhere and at any point in the future. This calls for setting immediate parameters of control to ISIS' outreach and influence sooner rather than later. ${ }^{19}$

\section{Notes}

1. The history and foundation of the group dates back to 1999 when Abu Mousab al-Zarqawi founded Jama'at al-Tawhid wa-al-Jihad. Its political and military characteristics, aims, and affiliations have changed over time, reflected in the frequent changes of its official name and references in the media (Zelin, 2014). In this article we refer to Islamic State by its most commonly used abbreviation in Arab-language media today: Da'esh, which translates to ISIS.

2. See al-Tamimi (2014). ISIS can be said to go as far as claiming jurisdiction over "true" Muslims worldwide, thereby forcing (at least) an ideological jurisdiction in other states.

3. Unprecedented reach: Schmid (2015). Easy prey: Coleman (2014); Shane and Hubbard (2014).

\section{Zelin (2014).}

5. Unique identity: This is also true for historic artifacts and artistic symbols in occupied territories that ISIS partly destroys and largely loots and sells on the black market, depending on their value. Artifacts of little value are destroyed as part of ISIS' creation of a new identity and those of significant value are sold to generate profit for the newly founded state (Caulderwood, 2014).

6. "[A] state consists of a territory with a significant and permanent population and with a government that has the capacity to conduct international relations" (Posner and Sykes, 2013, p. 39). Also see, Dorsey (2014).

7. An extension to a three populations scenario adds little to the qualitative results of the simpler case but excessively increases complexity. The three populations case can be made available to the interested reader.

8. The inefficiency of ISIS opponents' air strikes has been criticized. Further, air strikes are (ab)used by ISIS in that having contested a number of foreign armies, including some of the world's strongest, adds to ISIS' propaganda of fighting on "God's side."

9. Results remain unchanged if we assume that positive spillovers between and among groups exist, and that also a faction, which chooses strategy $s_{i n}$, partially benefits from atrocities of other factions and repelling the opposition. We could write $\pi_{i a}=a_{1} x+b_{1}(\bar{y}-y)$ and $\pi_{i n}=a_{2} x+b_{2}(\bar{y}-y)-c$. Since, however, the equilibria and dynamics are unaffected by a positive affine transformation of the payoffs, we can redefine $a=a_{1}-a_{2}$ and $b=b_{1}-b_{2}$ and obtain the original equations.

10. This does not imply that factions which refrain from atrocities are never attacked by the opposition. It is sufficient to see that such an attack is less likely in this case compared to the case in which the faction commits an atrocities. The argument is then equivalent to footnote 9 .

11. Classical game theory assumes a high degree of rationality and knowledge, see Aumann and Brandenburger (1995). In the evolutionary approach, payoff maximizing actions will diffuse by imitation. In addition, the probabilistic definition of the replicator dynamics also takes account of the case in which players sometimes switch to a lower payoff strategy (see Boyd and Richerson, 2002, for a discrete example), and generalizes a number of other updating algorithms (see Weibull, 1995, Section 5.3). The replicator dynamics can also be interpreted as representing the internal decisionmaking process of a collective. It replicates the considerations of the pros and cons of an action based on past experiences, as well as a trial and error period, whereby a player gradually converges to a best response. Ruling out unlikely Nash equilibria: The evolutionary stable equilibrium is asymptotically stable, proper, and trembling-hand perfect.

12. $(1-\bar{x})$ is a measure of public support for intervention. 
13. We linearize the dynamic system by splitting and adding the marginal effects of a change in $x$ and $y$, i.e., $\dot{x}=a_{11} x+a_{12} y$ and $\dot{y}=a_{21} x+a_{22} y$, with $a_{i j}$ being the appropriate elements of the Jacobian (i.e., for $\dot{x}=f(x)$, we have $a_{i j}=\delta f_{i} / \delta x_{j}$ ). Then any interior equilibrium $\left(x^{*}, y^{*}\right)$ is stable if its linearization is asymptotically stable, thus if no eigenvalue of the Jacobian has a strictly positive real part. For a one-dimensional system with only one type of player, two strategies, and the frequency $x$ of strategy 1 , the intuition is straight forward: The Jacobian is a one-dimensional matrix with eigenvalue $f^{\prime}(x)$. An interior equilibrium $x^{*}$ is stable, if $f^{\prime}(x)<0$, i.e., a marginal increase in $x$ will reduce the relative expected payoff for those players adhering to strategy 1 . For example, a shift of one player from strategy 2 to strategy 1 reduces the payoff for all those who follow strategy 1 , encouraging at least one player to switch to strategy 2 . As a consequence, $x$ will decrease again, and the equilibrium self-stabilizes.

14. This might sound counterintuitive for the reader. Consider that an unstable interior equilibrium defines the boundary of the basin of attraction of the adjacent equilibria, and thus their likelihood. If $x_{3}^{*}$ and $y_{3}^{*}$ define the basins of attraction of $x, y$ $=1$, an increase of the interior equilibrium implies that fewer points converge to $x, y=1$, rendering the equilibrium less likely.

15. If $\lambda_{23}<0$ then the point defined by equation (8) is a saddle point which will be upset by small random fluctuations.

16. Even though the graphs indicate a simple monotonic relationship between $a, b$ and the eigenvalues' real part, a closed-form solution could not be derived. Extending the analysis beyond the unit interval reveals that the relationship is not monotonic.

17. For larger benefits from atrocities, the system directly converges to the escalation outcome.

18. This behavior can be inferred from the shift of the $\dot{x}=0$ loci, which now intersect the abscissa.

19. Universal law: Qutb (1981).

\section{References}

Al-Tamimi, A.J. 2014. "The Dawn of the Islamic State of Iraq and Ash-sham." Current Trends in Islamic Ideology. Vol. 16, pp. 5-15. http://www.hudson.org/research/10173-

current-trends-in-islamist-ideology-volume-16 [accessed 23 August 2015].

Aumann, R.J. and A. Brandenburger. 1995. "Epistemic Conditions for Nash Equilibrium." Econometrica. Vol. 65, No. 5, pp. 1161-1180. http://dx.doi.org/10.2307/2171725

Boyd, R. and P.J. Richerson. 2002. "Group Beneficial Norms can Spread Rapidly in a Structured Population.” Journal of Theoretical biology. Vol. 215, No. 3, pp. 287-296. http://dx.doi.org/10.1006/jtbi.2001.2515

Caulderwood, K. 2014. "How ISIS Pillages, Traffics and Sells Ancient artifacts on Global Black Market." International Business Times. http://www.ibtimes.com/howisis-pillages- traffics-sells-ancient-artifacts-global-black-market-16050 44.

Coleman, A. 2014. "The Islamic State and International Law: An Ideological Rollercoaster?" Journal of the Philosophy of International Law. Vol. 5, No. 2, pp . 75-80.

Dorsey, J. 2014. "War Against Islamic State: Sowing Seeds of More Extremist Groups." RSIS Commentaries 190. Singapore: Nanyang Technical University.

Posner, E.A. and A.O. Sykes. 2013. Economic Foundations of International Law. Cambridge, MA: Belknap Press.

Qutb, S. 1981. Milestones. Riyadh: International Islamic Publishers.

Schmid, A.P. 2015. "Challenging the Narrative of the Islamic State." The Hague: International Centre for Counter-Terrorism.

Shane, S. and B. Hubbard. 2014. "ISIS Displaying a Deft Command of Varied Media. The New York Times (30 August 2014). http://www.nytimes.com/2014/08/31/world/ middleeast/isis-displaying-a-deft-command-of-varied-me dia.html?_r=0 [accessed 23 August 2015].

U.N. News Centre. 2015. Interview with Zainab Hawa Bangura, Special Representative of the Secretary-General on Sexual Violence in Conflict (14 April 2015). http://www.un.org/apps/news/newsmakers.asp?NewsID= 119 [accessed 23 August 2015].

Weibull, J.W. 1995. Evolutionary Game Theory. Cambridge, MA: The MIT Press.

Zelin, A.Y. 2014. "The War Between ISIS and al-Qaeda for Supremacy of the Global Jihadist Movement." Washington, D.C.: The Washington Institute for Near East Policy. http:/www.washingtoninstitute.org/uploads/Documents/ pubs/ResearchNote_20_Zelin.pdf [accessed 23 August $2015]$. 